\title{
ASSESSING THE SENSITIVITY OF SWMM TO VARIATIONS IN HYDROLOGICAL AND HYDRAULIC PARAMETERS: A CASE STUDY FOR THE CITY OF ISTANBUL
}

\section{AKDOĞAN Z. GÜVEN B. ${ }^{*}$}

Institute of Environmental Sciences

Boğaziçi University, 34342 Istanbul, Turkey

Received: $21 / 02 / 2016$

Accepted: 16/05/2016

*to whom all correspondence should be addressed:

Available online: 25/07/2016

e-mail: guven.basak@gmail.com

\begin{abstract}
Overland flow is highly affected by increasing urbanization, and variations in land use and climatic variables, especially in the last few decades. This necessitates the development of modeling approaches for planning and management of catchments that play a significant role on water supply. The main objective of this study is to determine the effects of major hydrological and hydraulic parameters on runoff production in the Alibeyköy Reservoir catchment area in Istanbul. Storm Water Management Model (SWMM) is chosen to develop the catchment hydrological model and the model's sensitivity is assessed based on the variations in eight major parameters of the model affecting runoff production. 55 years of time series precipitation data are used for model simulations. GIS-based maps including land use and land cover information are used to determine the imperviousness values required for SWMM. A oneat-a-time parametric sensitivity analysis is carried out to determine the most significant parameters affecting the model outcomes. Analysis results reveal that area of subcatchments, precipitation and conduit depth are the most significant parameters in SWMM affecting runoff production. Percent imperviousness and percent slope are the least significant parameters amongst other parameters influencing the output.
\end{abstract}

Keywords: SWMM; parameter sensitivity analysis; catchment hydrology; precipitation, imperviousness.

\section{Introduction}

The physically-based catchment hydrology models have been widely used, particularly in the last few decades, in order to better understand and interpret the behavior of surface and subsurface processes, as well as the mobility of water and contaminants. According to Jamieson et al. (2004), analysis tools and simulation models have been developed to properly evaluate alternate management practices and to predict water quality improvements at the catchment scale. During the hydrological modeling studies, water quality should be considered with runoff quantity due to the unequal distribution of water and its spatio-temporal variability at any place at any time. For this reason, it is important to have realistic models including hydrological or hydraulic component (e.g. Sappa et al., 2013), which have the appropriate spatial and temporal resolution required for the problem (Zoppou, 2001). In reference to catchment models, Environmental Protection Agency (EPA) Storm Water Management Model (SWMM) is the one model developed primarily for urban areas (Huber and Dickinson, 1988), which can clearly simulate the catchment hydrology and water quality.

The input data of a model can be affected by various uncertainties due to different sources of uncertainty, such as measurement errors or uncertainties introduced by inadequate definition. Hence, the model may

Akdoğan Z. and Güven B. (2016), Assessing the sensitivity of SWMM to variations in hydrological and hydraulic parameters: a case study for the city of Istanbul, Global NEST Journal, 18(4), 831-841. 
not be sufficiently reliable for correct conclusions (Crosetto et al., 2000). For this reason, sensitivity analysis can be applied to identify the significant parameters of computational models, and to explore the relationship between the output and the inputs. Sensitivity analysis can be described as the process of determining model output sensitivity to changes in its input parameters. In other words, sensitivity analysis of a mathematical model investigates how the uncertainty in the output of a model can be apportioned to different sources of uncertainty in the model input (Hamby, 1995), and involves analytical examination of input parameters to aid model validation and to provide guidance for future research and data requirements (Guven and Howard, 2011). According to Mulligan and Wainwright (2004), sensitivity analyses and subsequent derived information can be used for several purposes including:

i. better understanding the behavior of the model, particularly in terms of parameter interaction;

ii. verification of models;

iii. ensuring model parsimony by the rejection of parameters or processes to which the model is not sensitive;

iv. targeting field parameterization and validation programs for optimal data collection; and

v. providing a means of better understanding parts of or the whole system being modeled.

In literature there are several sensitivity analysis studies associated with catchment scale modeling, some of which are integrated with the GIS software (Mohammed et al., 2004; Muleta and Nicklow, 2005; Pandey et al., 2008). This paper aims to evaluate the use of GIS incorporated SWMM modeling as a methodological approach in rainfall-runoff analysis and to assess the significant parameters affecting model outcomes. For this purpose, a semi-distributed, GIS-based catchment hydrology model is developed for the Alibeyköy Reservoir in Istanbul, using time-series precipitation, topographical data and land use information, and the sensitivity of the model to the changes in major parameters are evaluated.

\section{Methodology}

A semi-distributed, physically-based catchment hydrology model is developed for the Alibeyköy Reservoir to investigate the parametric sensitivities of a widely used urban hydrology model. GIS and SWMM are used as major modeling tools for catchment delineation and runoff estimation, respectively. Furthermore, a one-at-a-time parameter sensitivity analysis is carried out by changing the values of eight selected parameters by $10 \%$ increments within a range of $100 \%$, from $-50 \%$ to $+50 \%$, to determine the most significant ones affecting the model output.

\subsection{Study Area}

Alibeyköy Reservoir is one of the main seven reservoirs supplying potable water to the megacity Istanbul. It was established in 1972 on the European side of the city. Annual mean precipitation in the catchment is $800 \mathrm{~mm}$ and mainly falls between November and January. The reservoir is of great importance with its $160 \mathrm{~km}^{2}$ drainage area and 65 million $\mathrm{m}^{3}$ water capture capacity (Seker et al., 2003). It provides 3.4\% of daily drinking water supply $\left(98600 \mathrm{~m}^{3}\right.$ ) of the city (Ustun, 2010). The main tributaries contributing to the dam are Alibey Stream, Cebeci Stream, Boğazköy Stream, Bolluca Stream, Gülgen Stream, Ayvali Stream, Malkoç Stream, and Çiftepinar Stream (Ozdemir and Akar, 2009). Approximately 65\% of the catchment is covered by forests, while $18 \%$ of the region consists of bare lands. The population of the districts located in the catchment has almost doubled within the years of 1990 to 2000 (Musaoglu et al., 2006), which has contributed to urbanization and has altered the land cover of the reservoir, especially in the southern part. The urbanization percentage in the southern part of the catchment is 80 approximately. The location and boundaries of Alibeyköy Reservoir are demonstrated in Fig.1. 


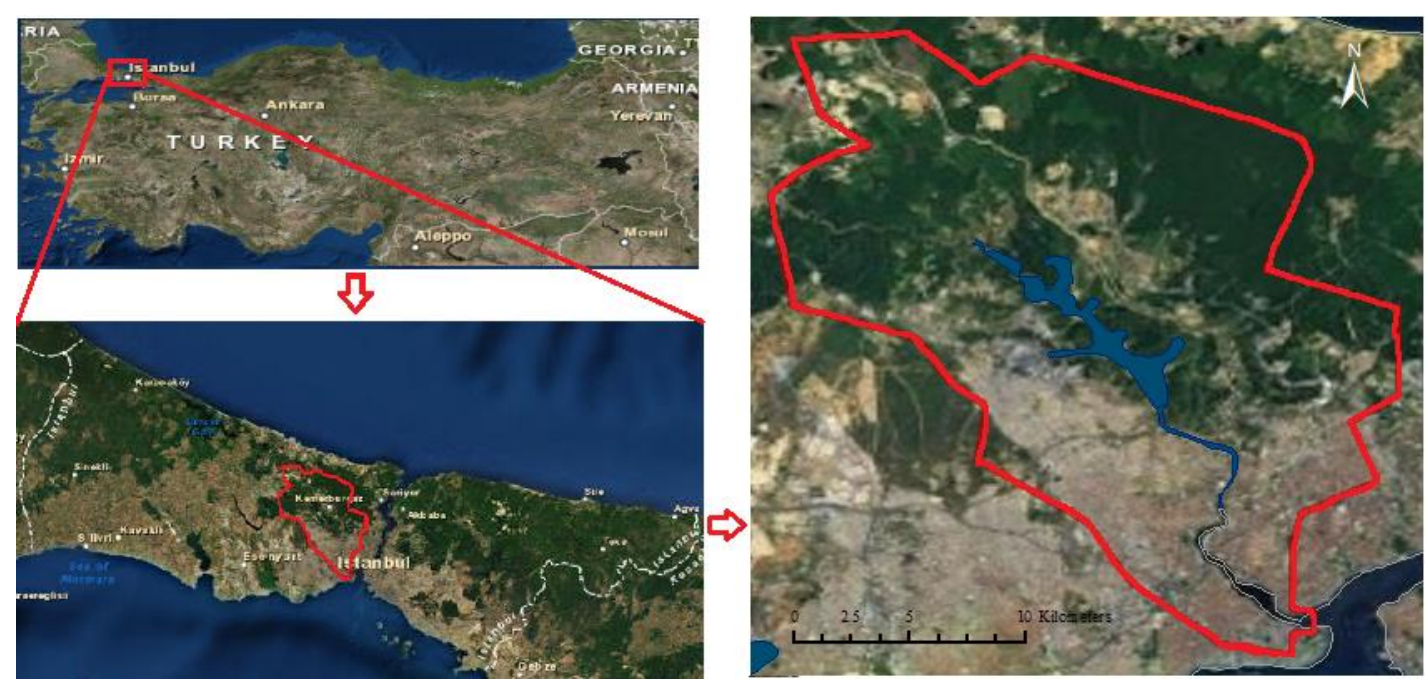

Figure 1. Map of the study area

\subsection{Modeling Catchment Hydrology}

In this study, GIS-based digital elevation maps are used to obtain topographical data, such as elevation, slope, area, and width, and to prepare the background map to be used for the hydrological model. The topographical data and discretized catchment obtained by ArcGIS are transferred to SWMM for the construction of the hydrological model. SWMM is preferred because of its suitability for hydrological modeling procedure in urban areas (Huber and Dickinson, 1988) and convenience to operate with spatial interface. The catchment map including flow accumulation information represented in Fig. 2a is used as backdrop image in SWMM, and precipitation station and other hydrological elements are located on the map (Fig. 2b). In order to increase the sensitivity and accuracy of the hydrological model, the catchment is further divided into four subcatchments in SWMM. After placing the junctions of the rivers and rain gages, the conduits indicating the stream network are drawn. Input parameters including topographical data and land use information, time-series precipitation, and other required data produced by the SWMM are also entered to the model. A schematized representation of the modeling procedure and information flow is summarized in Fig. 3.

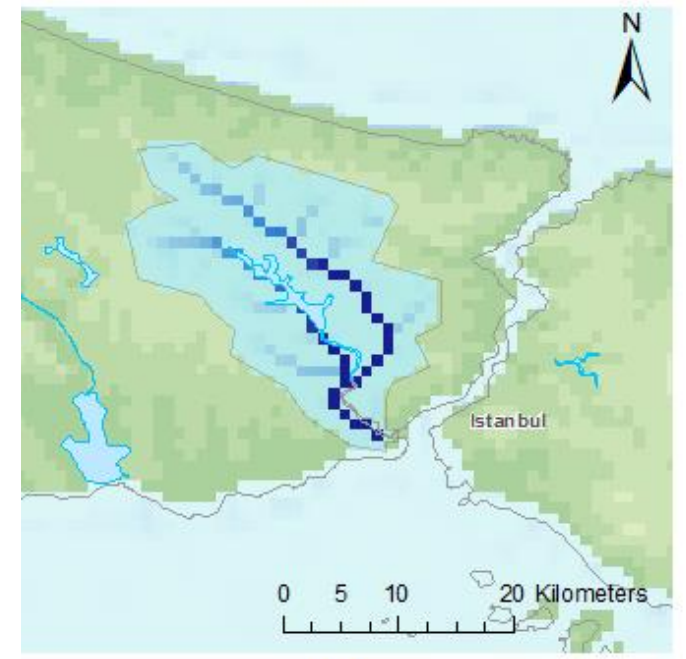

(a)

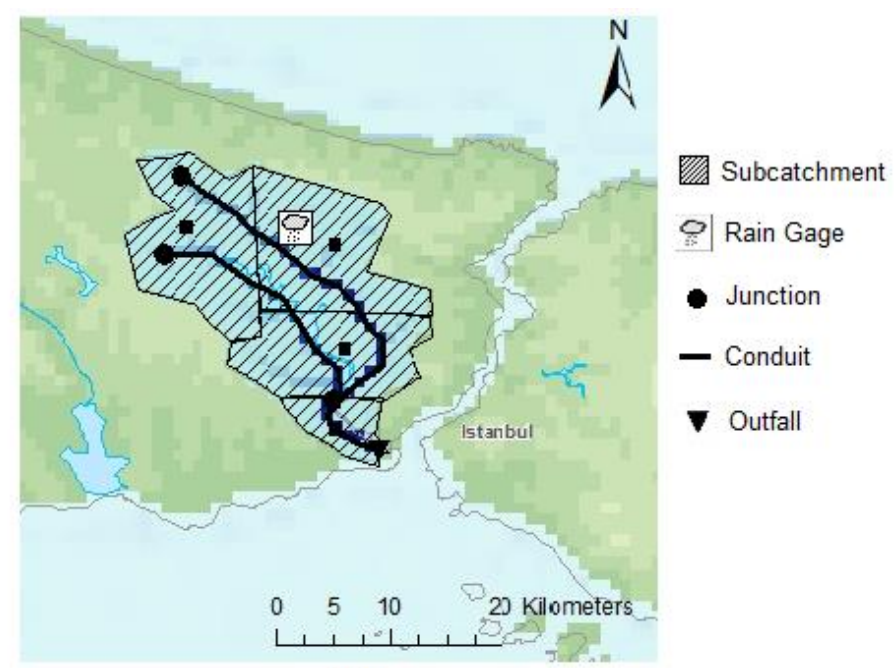

(b)

Figure 2. The discretizated catchment (a) flow accumulation map (b) SWMM layout map 


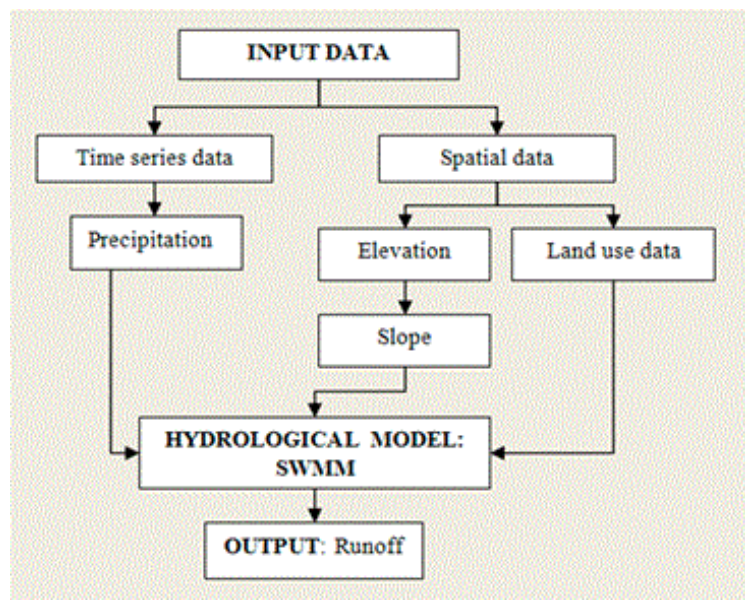

Figure 3. A schematized representation of the modeling procedure and associated data requirements

Availability of daily precipitation data is particularly crucial to develop and run hydrological models, as conversion of rainfall to runoff is the first step in most of the models dealing with catchment hydrology (Varanou et al., 2002; Shigaki et al., 2007; Visser et al., 2012). In this study, the required meteorology stations, their latitudes and longitudes, and associated rainfall intensities are obtained from the Turkish Meteorological Service. Bahçeköy Precipitation Station is chosen to provide daily precipitation data between years 1950 and 2005, to be transferred to SWMM program.

It is possible to classify the variables and parameters under two main categories as the quantities describing subcatchment and hydraulic characteristics as outlined in Table 1. While the topographical data describing the characteristics of subcatchments and hydraulic parameters regarding rivers are determined via GIS, values of parameters such as Manning's coefficient, depression storage depths, and conduit roughness for natural channels are obtained from the literature. Values and corresponding sources of such data are given in Table 2.

Table 1. The parameters required for the hydrological model.

\begin{tabular}{cc}
\hline Subcatchment Characteristics & Hydraulic Characteristics \\
\hline Area & Invert elevation of junction \\
\hline Width & Conduit length \\
\hline \% Slope & Max depth \\
\hline \% Imperviousness & Conduit roughness \\
\hline Land use & Conduit slope \\
\hline
\end{tabular}

Runoff volumes produced in subcatchments are highly affected by the changes in land use categories, such as residential, commercial and rural areas. In this respect runoff coefficients of different land use classes are used to help to characterize the amount of runoff produced in each subcatchment. SWMM produces runoff coefficients and applies the well-known rational method (Eq. 1) for each subcathment area to establish a relationship between time-series precipitation and surface runoff.

\section{Runoff=Subcatchment Area $\times$ Annual Rainfall $\times$ Runoff Coefficient}

The \% imperviousness values used for the estimation of surface runoff are determined by the help of land use information, which is available for the year 2005, within the catchment boundaries. This information was derived from the GIS-based maps obtained from Republic of Turkey Ministry of Food, Agriculture and Livestock, and also included the land use and land cover data of the provinces in the region. The maps illustrating the residential, commercial and rural areas are then transferred to SWMM, and each subcatchment is magnified to be able to analyze the land use percentages. The imperviousness values for all subcatchments are estimated via using runoff coefficients that are corresponding to three main land use classes; commercial, residential and rural. 
Table 2. Input data for subcatchments and conduits.

\begin{tabular}{cclc}
\hline Parameter & Value & \multicolumn{1}{c}{ Description } & Source \\
\hline N-imperv & 0.011 & $\begin{array}{l}\text { Manning's } \mathrm{n} \text { for overland flow over the } \\
\text { impervious portion of the subcatchment }\end{array}$ & $\begin{array}{c}\text { McCuen et al., } \\
1996\end{array}$ \\
N-perv & 0.13 & $\begin{array}{l}\text { Manning's n for overland flow over the pervious } \\
\text { portion of the subcatchment }\end{array}$ & \\
\hline
\end{tabular}

D-store-imperv $\quad 1.27 \mathrm{~mm}$ Depth of depression storage on the impervious portion of the subcatchment

\begin{tabular}{ccll}
\hline D-store-perv & $3.8 \mathrm{~mm}$ & $\begin{array}{l}\text { Depth of depression storage on the pervious } \\
\text { portion of the subcatchment }\end{array}$ & ASCE, 1992 \\
\hline Conduit Roughness & 0.03 & Manning's roughness coefficient & ASCE, 1982 \\
\hline
\end{tabular}

\subsection{Parameter Sensitivity Analysis}

Sensitivity analysis is carried out to test the level of significance of the parameters that are associated with runoff quantity. The effect of variations in imperviousness, subcatchment area, slope and precipitation are evaluated by against the variations in subcatchment runoff amount, and parametric sensitivities of conduit roughness, maximum depth of conduit, conduit length, and invert elevation of junction are evaluated against the percent variations in total inflow volume at outfall point of catchment. The value of each selected parameter are changed by $10 \%$ increments within a range of $100 \%$, from $-50 \%$ to $+50 \%$, and model outputs for the year 1997 are observed. A one-at-a-time parameter sensitivity analysis is applied by changing one parameter at a time, while holding the others fixed. The relative sensitivities of results to eight different parameters of the model are determined by taking into account the model output variations that originates from the changes in input parameters. The relative variation is calculated by using the Eq(s). 2 and 3 (Dubus et al., 2003):

$$
\begin{aligned}
& \text { Input Variation }=\frac{I-I_{B C}}{I_{B C}} \times 100 \\
& \text { Output Variation }=\frac{O-O_{B C}}{O_{B C}} \times 100
\end{aligned}
$$

where; $I$ is the value of input parameter, $\mathrm{I}_{\mathrm{BC}}$ is the value of input parameter for the base-case scenario, $\mathrm{O}$ is the value of output variable, and $\mathrm{O}_{B C}$ is the value of output variable for the base-case scenario. Subsequently, the ratio of variation (ROV) is calculated as follows (Dubus et al., 2003)

$$
\begin{aligned}
& \text { ROV }=\frac{\text { Output Variation }}{\text { Input Variation }} \\
& \text { ROV }=\frac{O-O_{B C}}{I-I_{B C}} \times \frac{I_{B C}}{O_{B C}}
\end{aligned}
$$

\section{Results and Discussion}

\subsection{Results of the Hydrological Model}

Prior to model set up, the wettest and relatively dry years are determined in order to conduct extreme case studies. After the model was run, the system precipitation and runoff graphs are produced by SWMM, to see whether the model captures the relationship between rainfall and runoff in a reasonable manner. According to the data obtained by Turkish Meteorological Service, the wettest and driest years 
are 1997 and 1989, respectively, and the simulation period is chosen between October and December in those years. As can be seen from Fig. 4, there is a visible difference between the runoff productions belonging these years, suggesting that as precipitation increases, the runoff production of the system increases and the model simulates well in terms of the ratio between precipitation and runoff production for the whole system.

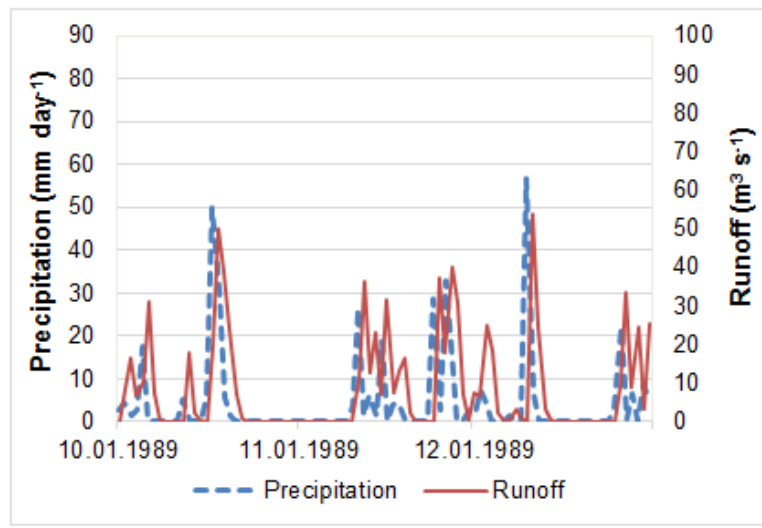

(a)

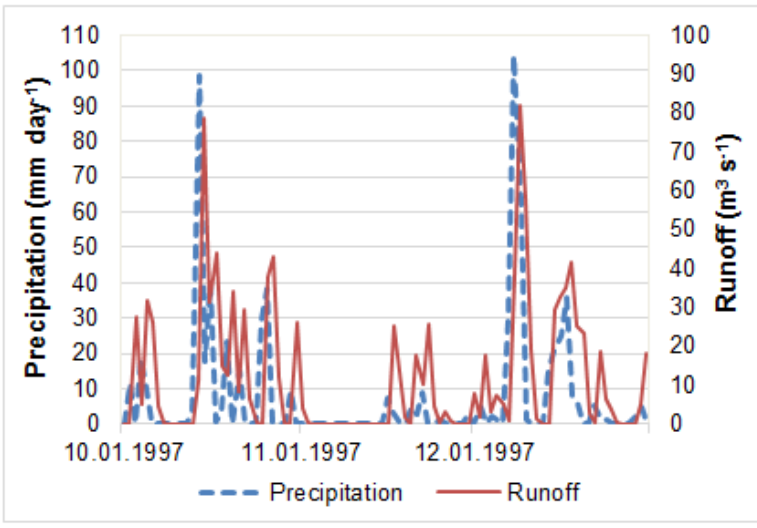

(b)

Figure 4. Precipitation vs. runoff results (a) system runoff for Oct-Dec, 1989,

(b) system runoff for Oct-Dec, 1997

\subsection{Results of the Parameter Sensitivity Analysis}

The influences of \% imperviousness, area, \% slope, precipitation, conduit roughness, maximum depth of conduit, conduit length, and invert elevation of junction on runoff volume are assessed.

\subsubsection{Sensitivity of SWMM to Hydrological Parameters}

According to the analysis results, \% imperviousness has a slight and positive influence on model outcome. As the amount of impervious surfaces increases, more runoff is created and less water is able to infiltrate into the ground. In order to provide a better understanding of the sensitivity of \% imperviousness, runoff results for the year 1997 are demonstrated in Fig. 5a. The accelerated increase in model outcome is attributed to exponential imperviousness equations used in SWMM.

The area of subcatchment that collects precipitation has a positive correlation with runoff production. Fig. $5 \mathrm{~b}$ indicates that, as the area of collection increases, output runoff amount from subcatchment increases, almost linearly. According to a previous research (Brezonik and Stadelmann, 2002), drainage area and precipitation amount are the most important variables to predict event loads, which are associated with runoff volume. The result provided from the sensitivity analysis of area parameter also confirms that this parameter has a high influence on model outcome as indicated on Fig. $5 b$.

As can be seen from Fig. $5 c$, model outputs are not very sensitive to the changes in slope values. The slightly increasing trend in the graph confirms that with increasing slope, the time spent to leave the area decreases further decreasing routing value and increasing peak flow during the times of rain (Horton, 1933). A previous study carried out by El-Hassanin et al., (1993) also reveal that runoff-rainfall ratios are high under the steep slopes and soil loss per unit of rainfall and also per unit of runoff increase as the slope gradient increase.

As being the most governing process that affects runoff (Horton, 1933), precipitation also plays a dominant role in both soil loss and sediment delivery (Nearing et al., 1990). Fig. 5d clearly agrees published literature by suggesting the positive relation between the rainfall and runoff production. 


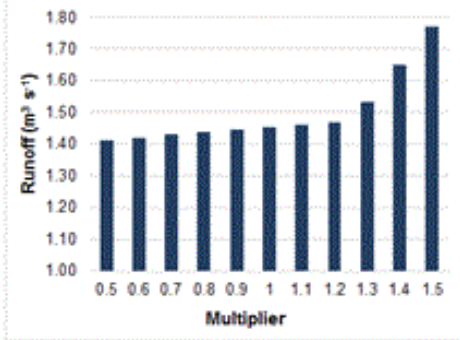

(a)

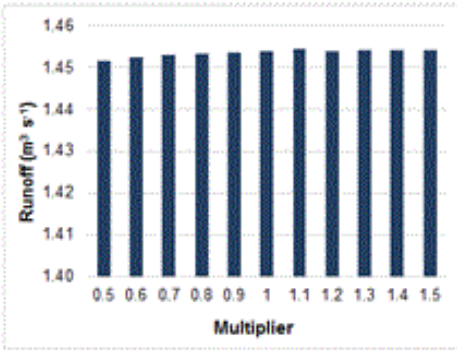

(c)

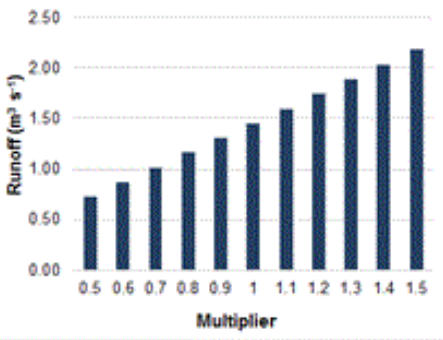

(b)

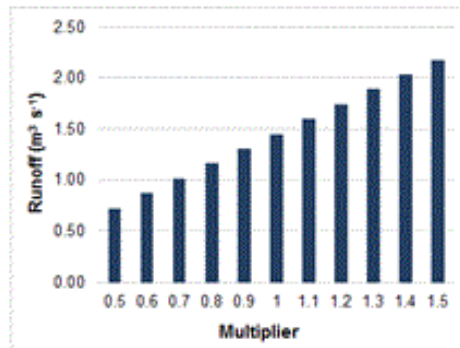

(d)

Figure 5. Model runoff results of subcatchments with respect to various (a) \% imperviousness, (b) area, (c) \% slope, (d) precipitation

\subsubsection{Sensitivity of SWMM to Hydraulic Parameters}

In this study, conduit roughness parameter of SWMM stands for the Manning's coefficient for the natural channel. According to the analysis results, conduit roughness has an inverse influence on total inflow volume (Fig. 6a). Channel having a low roughness value put less resistance to water, hence maximum flows of stormy days are higher in the channels that have low roughness (Horton, 1933).

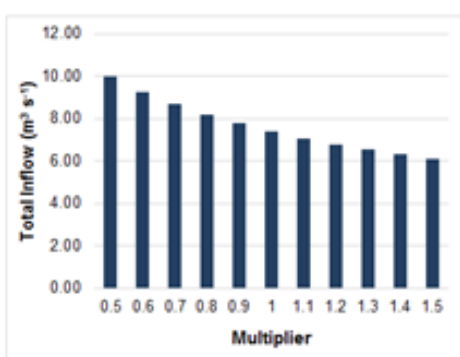

(a)

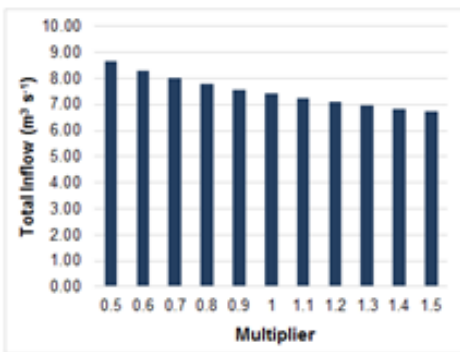

(c)

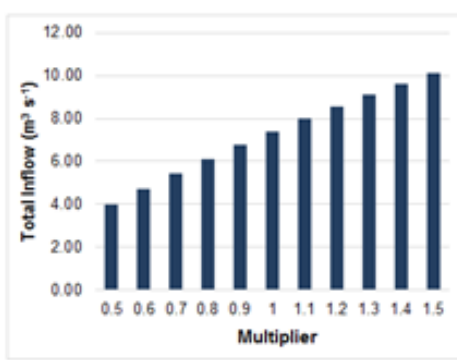

(b)

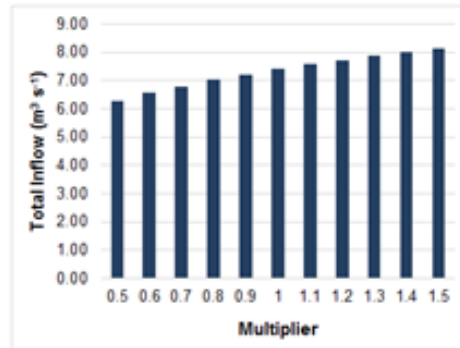

(d)

Figure 6. Model runoff results of outfall of catchment with respect to various (a) conduit roughness, (b) conduit max. depth, (c) conduit length, (d) invert elevation of junction.

Maximum depth of the river has a quite pronounced effect on model outcomes, thus must be determined with caution. The graph represented in Fig. $6 \mathrm{~b}$ indicates a positive correlation between maximum depth of the conduit and model inflow results. 
Conduit length has also a considerable influence on model outcomes. As can be seen from Fig. $6 \mathrm{c}$, there is an inverse proportion between conduit length and total inflow, which is attributed to larger flow routing and increased time for water to leave the conduit with increasing length of the river.

According to the results, invert elevation of the junction, which also determines the slope of the river, has a moderate influence on model outcomes. The graph demonstrated in Fig. $6 \mathrm{~d}$ reveals that as junction elevation and associated conduit slope increase, the time spent to leave the channel decrease, thus more inflow is generated. These results are in agreement with the previous published literature (Horton, 1933; El-Hassanin et al., 1993).

\subsubsection{Overall Evaluation of the Sensitivity Analysis}

In order to provide a better understanding of the sensitivity of SWMM to changes in various parameters, output variations of each parameter and their ratio of variations (ROV) are determined as shown in Fig. $7 \mathrm{a}$ and $7 \mathrm{~b}$, respectively. The parameters are then classified according to their importance ranking and a subjective sensitivity class is assigned to each assessed parameter as given in Table 3. The outcome of the sensitivity analysis reveal that area, precipitation and conduit depth are the most important parameters and conduit roughness has a considerable influence on model output. While conduit length and invert elevation of junction have an average influence, percent imperviousness and percent slope are the least significant parameters affecting the output. The results of the analysis are in accordance with the previous published literature (Nearing et al., 1990; El-Hassanin et al., 1993).

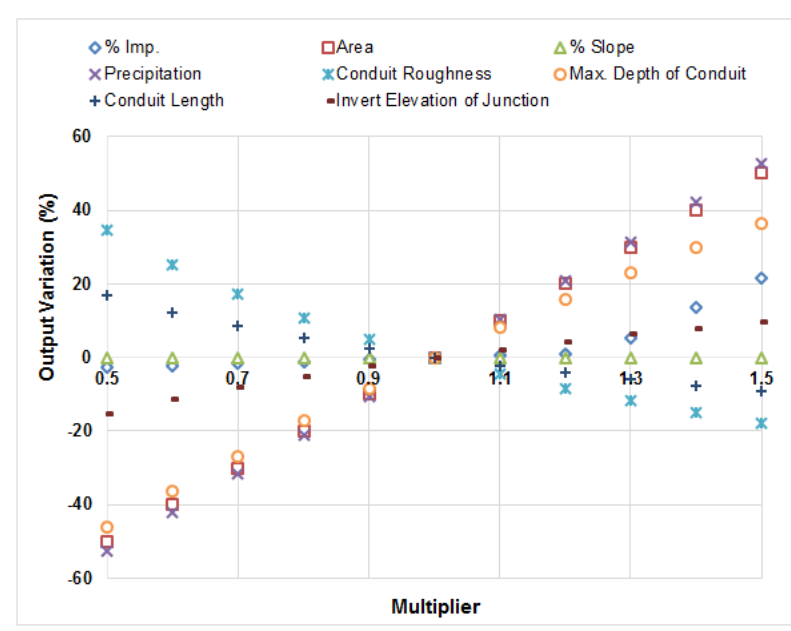

(a)

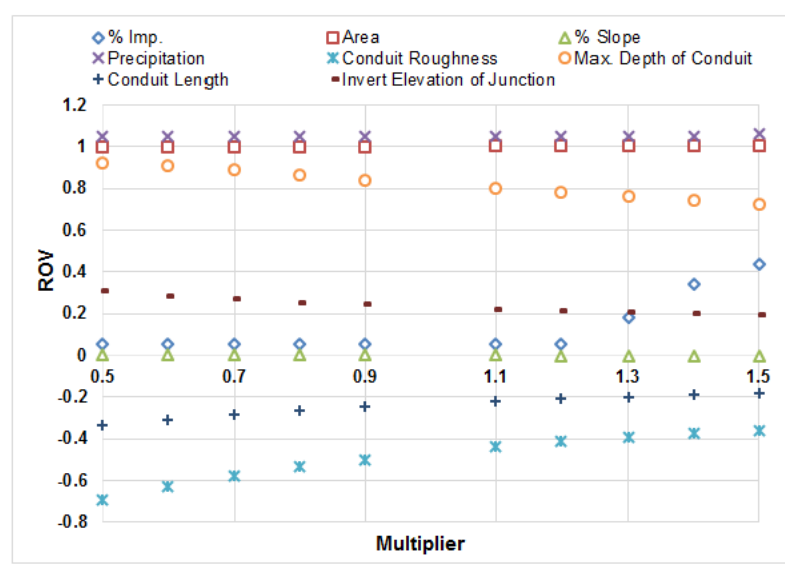

(b)

Figure 7. Parametric sensitivities (a) Output Variation vs Multiplier, (b) Ratio of Variation vs Multiplier. 
Table 3. Parameter sensitivity classification and ranking.

\begin{tabular}{cccc}
\hline Parameter & Sensitivity Class & Correlation & Sensitivity Rank \\
\hline Precipitation & Very High & Direct & 1 \\
\hline Area & Very High & Direct & 2 \\
\hline Maximum Depth of Conduit & Very High & Direct & 3 \\
\hline Conduit Roughness & High & Inverse & 4 \\
\hline Conduit Length & Medium & Inverse & 5 \\
\hline Invert Elevation of Junction & Medium & Direct & 5 \\
\hline$\%$ Imperviousness & Low & Direct & 7 \\
\hline \% Slope & Very Low & Direct & 8 \\
\hline
\end{tabular}

Consequently, it can be recommended that extreme caution should be taken in the determination of significant parameters, in particular. In this study, as being one of the most sensitive parameters, precipitation values were directly obtained from real data, and catchment/subcatchment areas were automatically derived by the GIS supported SWMM program. The average slope values were assumed as lumped parameters, since these were initially determined by the GIS. So, any problems that can be attributed to this lumped assumption of the slope parameter will be hampered by the fact that \% slope is the least significant parameter amongst the model parameters assessed for their sensitivities.

\section{Conclusions}

The aim of the study presented here is to develop a catchment hydrology model for Alibeyköy Reservoir, to observe the effect of changes in hydrological and hydraulic variables, and land use characteristics on runoff production, and to assess the most significant parameters affecting SWMM outcomes. In the present modeling study, the topographical and land use characteristics of each subcatchment, such as area, width, and \% imperviousness are calculated by using GIS. The hydraulic characteristics of rivers, such as junction elevation, conduit length, and channel slope are also estimated via GIS based maps by taking into account the spatial distributions of such parameters. On the other hand, maximum depth of the channels, Manning's coefficient, depression storage depths, and channel roughness values are selected from the literature and the average \% slope values for catchments are considered as lumped parameters and a semi-distributed hydrological model is developed. The GIS based maps and derived data together with input variables are then incorporated to the modeling environment, SWMM, for the simulations of runoff. Rainfall-runoff model illustrates that high rainfall events contribute significantly to runoff production in catchment, and the model simulates in a reasonable manner, so that further analysis can be carried out.

A one-at-a-time parametric sensitivity analysis procedure is carried out to determine the sensitivity ranking of parameters affecting SWMM's simulation results. According to the analysis results, the most significant parameters include precipitation, area, and maximum depth of conduit. The model is also quite sensitive to changes in conduit roughness, while conduit length and invert elevation of junction have an average influence. On the other hand, \% imperviousness and \% slope have the lowest influence on model outputs. One important outcome of this analysis presented here is that the results are likely to guide field studies for data collection, and modelers for calibration and parameterization.

Data gathering and harmonization are one of the most challenging steps towards developing distributed catchment models due to the spatial variability of data. This study also suggests that GIS incorporated SWMM modeling approach is an efficient tool in catchment modeling in terms of the derivation of input parameters for catchment hydrology, determination of the effect of meteorological and land use changes on runoff production. Therefore, SWMM integrated with GIS has the potential to evaluate the storm rainfall and pollution prevention planning. Further research may focus on developing catchment hydrology and runoff quality models in a more distributed manner, especially using remote sensing techniques and GIS (e.g. Weng, 2001; Sappa et al., 2013), to account for the rather high spatio-temporal 
variability of catchments. Thus, more comprehensive evaluation and management mechanism for catchments can be undertaken and pollutant prevention programs in receiving waters can be developed.

\section{Acknowledgements}

This study was supported by Boğaziçi University Scientific Research Projects (Boğaziçi University Research Fund BAP, Project No: 6643).

\section{References}

ASCE (1982), Gravity Sanitary Sewer Design and Construction, American Society of Civil Engineers, New York.

ASCE (1992), Design \& Construction of Urban Stormwater Management Systems, American Society of Civil Engineers, New York.

Brezonik P.L. and Stadelmann T.H. (2002), Analysis and predictive models of stormwater runoff volumes, loads, and pollutant concentrations from watersheds in the Twin Cities metropolitan area, Minnesota, USA, Water Research, 36, 1743-1757.

Crosetto M., Tarantola S. and Saltelli A. (2000), Sensitivity and uncertainty analysis in spatial modeling based on GIS, Agriculture, Ecosystems and Environment, 81, 71-79.

Dubus I.G., Brown C.D. and Beulke S. (2003), Sensitivity analyses for four pesticide leaching models, Pest Management Science, 59, 962-982.

El- Hassanin A.S., Labib T.M. and Gaber E.I. (1993), Effect of vegetation cover and land slope on runoff and soil losses from the catchments of Burundi, Agriculture, Ecosystems and Environment, 43, 301-308.

Guven B. and Howard A. (2011), Sensitivity analysis of a cyanobacterial growth and movement model under two different flow regimes, Environmental Modeling and Assessment, 16, 577-589.

Hamby D. M. (1995), A comparison of sensitivity analysis techniques, Health Physics, 68, 195-204.

Horton R.E. (1933), The role of infiltration in the hydrologic cycle, Transactions, American Geophysical Union, 14, 446-460.

Huber W.C. and Dickinson R.E. (1988), Storm water management model, version 4: User's manual, EPA- 600/388/001a, U.S. EPA, Georgia.

Jamieson R., Gordon R., Joy D. and Lee H. (2004), Assessing microbial pollution of rural surface waters: A review of current catchment scale modeling approaches, Agricultural Water Management, 70, 1-17.

McCuen R., Johnson P.A. and Ragan R.M. (1996), Highway Hydrology, U.S. Department of Transportation, Federal Highway Administration, Washington, D.C.

Mohammed H., Yohannes F. and Zeleke G. (2004), Validation of agricultural nonpoint source (AGNPS) pollution model in Kori catchment, South Wollo, Ethiopia, International Journal of Applied Earth Observation and Geoinformation, 6, 97-109.

Muleta M.K. and Nicklow J.W. (2005), Sensitivity and uncertainty analysis coupled with automatic calibration for a distributed catchment model, Journal of Hydrology, 306, 127-145.

Mulligan M. and Wainwright J. (2004), Modelling and model building, In: Environmental Modelling: Finding Simplicity in Complexity, Mulligan M. and Wainwright J. (Eds.), Wiley, UK.

Musaoglu N., Gurel M., Ulugtekin N., Tanik A. and Seker D.Z. (2006), Use of remotely sensed data for analysis of landuse change in a highly urbanized district of mega city, Istanbul, Journal of Environmental Science and Health, 41, 2057-2069.

Nearing M.A., Deer-Ascough L. and Laflen J.M. (1990), Sensitivity analysis of the WEPP hillslope profile erosion model, American Society of Agricultural Engineers (ASAE), 33(3), 839-849.

Ozdemir Y. and Akar I. (2009), Determination of land-use features in Alibeyköy Dam and vicinity by using multitemporal satellite imagery and GIS, In: TMMOB Geographical Information Systems Conference, Izmir, November 2-6.

Pandey A., Chowdary V.M., Mal B.C. and Billib M. (2008), Runoff and sediment yield modeling from a small agricultural catchment in India using the WEPP model, Journal of Hydrology, 348, 305-319. 
Sappa G., Ferranti F., Ergul S. and loanni G. (2013), Evaluation of the groundwater active recharge trend in the coastal plain of Dar es Salaam (Tanzania), Journal of Chemical and Pharmaceutical Research, 5(12), 548-552.

Seker D.Z., Kabdasli S. and Rudvan B. (2003), Risk assessment of a dam-break using GIS technology, Water Science and Technology, 48, 89-95.

Shigaki F., Sharpley A. and Prochnow L.I. (2007), Rainfall intensity and phosphorus source effects on phosphorus transport in surface runoff from soil trays, Science of the Total Environment, 373, 334-343.

Ustun B. (2010), Alibeyköy Dam review and evaluation report, TMMOB Çevre Mühendisleri Odasi, Istanbul.

Varanou E., Gkouvatsou E., Baltas E. and Mimikou M. (2002), Quantity and quality integrated catchment modeling under climate change with use of Soil and Water Assessment Tool model, Journal of Hydrologic Engineering, 7(3), 228-244.

Visser A., Kroes J., van Vliet M.T.H., Blenkinsop S., Fowler H.J. and Broers H.P. (2012), Climate change impacts on the leaching of a heavy metal contamination in a small lowland catchment, Journal of Contaminant Hydrology, 127, 47-64.

Weng Q. (2001), Modeling Urban Growth Effects on Surface Runoff with the Integration of Remote Sensing and GIS, Environmental Management, 28(6), 737-748.

Zoppou C. (2001), Review of urban storm water models, Environmental Modeling and Software, 16, 195-231. 